\title{
Postoperative Thrombocytosis after Coronary Artery Bypass Grafting: A Potential Danger even after Hospital Discharge
}

\author{
Jan T. Christenson François Simonet Martin Schmuziger \\ Department of Cardiology and Cardiovascular Surgery, Hôpital de la Tour, Meyrin-Geneva, \\ Switzerland
}

\author{
Key Words \\ Thrombocytosis • Coronary artery disease • \\ Vein graft occlusion - Serum cholesterol . \\ HDL cholesterol · Coronary artery bypass \\ grafting
}

\begin{abstract}
Objective: Thrombocytosis (platelet counts $>400 \times 10^{3} / \mathrm{mm}^{3}$ ) following coronary artery bypass grafting has been described to occur frequently (20-30\%) and to be associated with thrombotic complications postoperatively. The purpose of the present study is to establish when the peak value of platelet count occurs, and how high it is, as well as to determine the duration of thrombocytosis. Methods: Thirty consecutive patients undergoing elective coronary artery bypass grafting, who subsequently developed postoperative thrombocytosis (group 1) were considered for the study. Another 30 patients
\end{abstract}

\begin{tabular}{ll}
\hline KARGER & (1) 1999 S. Karger AG, Basel \\
Fax +41 61 306 1234 34 & \\
$\begin{array}{l}\text { E-Mail karger@karger.ch } \\
\text { www.karger.com }\end{array}$ & $\begin{array}{l}\text { Accessible online at: } \\
\text { http://BioMedNet.com/karger }\end{array}$
\end{tabular}

with platelet counts within normal limits postoperatively served as controls (group 2). Platelet count was monitored on a weekly basis during 5 weeks postoperatively. Patient characteristics, operation data and cardiopulmonary bypass data in group 1 did not differ from group 2 patients, except for a higher incidence of hyperlipidemia, i.e., 97\% (29/30 patients) in group 1 compared to $40 \%$ (12/30) in group 2 ( $p<0.001$ ). Results: Neither deaths nor nonfatal myocardial infarctions occurred during the study period. Postoperative thrombocytosis was diagnosed on $6.1 \pm$ 1.5 days postoperatively, and peak platelet count reached $14 \pm 4.0$ days postoperatively (6-21 days). The highest platelet count observed was $905,000 / \mathrm{mm}^{3}$. Platelet counts returned to normal values within 5 weeks. Three late vein graft occlusions occurred in all groups, and thus coinciding with the maximum platelet count observed. Conclusions: Postoperative thrombocytosis is a potentially

Prof. Jan T. Christenson, MD

Department of Cardiology and Cardiovascular Surgery Hôpital de la Tour, 1 av. J.-D. Maillard

CH-1217 Meyrin-Geneva (Switzerland), Tel. +41 227800303

Fax +41 22 7851653, E-Mail JTChristenson@latour.ch 
dangerous complication, with an increased risk for vein graft occlusion. Postoperative thrombocytosis, when it occurs, is diagnosed around the 6th postoperative day, reaches its peak 2 weeks postoperatively and may last as long as 5 weeks. Close surveillance of patients with postoperative thrombocytosis is emphasized.

\section{Introduction}

Major surgical procedures, including cardiac surgery, are known to be followed by altered platelet behavior. A decrease in platelet count during cardiopulmonary bypass (CPB) is well documented [1]. Thrombocytopenia and platelet dysfunction, causing postoperative bleeding after cardiac surgery, have been the main concern of most cardiac surgeons. Following the initial decrease in the platelet count after CPB, a pronounced increase both in the platelet count and in the platelet adhesiveness and aggregation occurs [1]. Recently, we have demonstrated that an overwhelming (thrombocytosis, platelet counts $>450 \times 10^{3} / \mathrm{mm}^{3}$ ) postoperative increase in platelet count occurs in a large proportion of patients (20\%) undergoing coronary artery bypass grafting (CABG) [2]. This postoperative thrombocytosis was found to be associated with an increased frequency of late thrombotic complications, e.g. late ( $>1$ week postoperatively) vein graft occlusion and myocardial infarction [2].

In a prospective study, it was demonstrated that hypercholesterolemia was significantly more frequently present in patients who subsequently developed thrombocytosis, while hemostasis and various anti-inflammatory parameters did not differ from controls. It was speculated that postoperative thrombocytosis could be linked to a lipid dysfunction
[Lipoprotein (a)] and thus has a genetic connection [3].

Postoperative thrombocytosis is usually diagnosed within 1 week following surgery, but its maximum level is still unknown and the duration of this potentially dangerous complication has not yet been established, which is the purpose of this study.

\section{Methods}

\section{Study Groups}

Thirty consecutive patients admitted for elective CABG who subsequently developed postoperative thrombocytosis, defined as a platelet count greater than $400 \times 10^{3} / \mathrm{mm}^{3}$ (upper normal limit in our laboratory), were included in this study (group 1), and compared to 30 consecutive patients admitted for elective CABG and who did not develop postoperative thrombocytosis (controls, group 2). Exclusion criteria for both groups were: preoperative low platelet count (150 $\times 10^{3} / \mathrm{mm}^{3}$ ), recent blood transfusion of any kind (within 7 days prior to surgery), emergency operation, ongoing infections (antibiotic therapy) and patients who had received anticoagulation therapy (heparin or coumarine) within 7 days prior to surgery.

Patients were enrolled into the study between January 1, 1996 and January 1, 1997. Preoperative patient characteristics, operative data, CPB data and postoperative complications were entered into a database (Digital $^{\mathrm{TM}}$, Digital Equipment Corp., Geneva, Switzerland), together with preoperative routine blood chemistry and hematology results. Repeated blood samples for platelet count and serum lipid levels were obtained during the 1st week postoperatively and on a weekly basis thereafter up to 5 weeks postoperatively. The clinical status of the patients was closely monitored and if renewed cardiac symptoms occurred during the study period, the patients were fully investigated, including repeated coronary angiography, which otherwise is not performed on a routine basis.

All patients were anticoagulated postoperatively (which was the routine in our institution during the study period), initially with heparin followed by coumarin. All patients in group 1 received an additional treatment with $100 \mathrm{mg}$ acetylsalicylic acid daily, once postoperative thrombocytosis was diagnosed. Adhesivity tests were performed during peak thrombocytosis. 
Table 1. Patient characteristics in 30 consecutive patients undergoing CABG who postoperatively developed thrombocytosis (group 1) and 30 consecutive patients undergoing CABG with postoperative platelet counts within normal limits (controls, group 2)

\begin{tabular}{|c|c|c|c|c|c|}
\hline & \multicolumn{2}{|c|}{ Group 1} & \multicolumn{2}{|c|}{ Group 2} & \multirow[t]{2}{*}{$\mathrm{p}$ value } \\
\hline & $\mathrm{n}$ & $\%$ & $\mathrm{n}$ & $\%$ & \\
\hline Age, years & \multicolumn{2}{|c|}{$62.0 \pm 11.0$} & \multicolumn{2}{|c|}{$62.8 \pm 16.3$} & \multirow[t]{2}{*}{ NS } \\
\hline Range & 49 & -83 & 26 & -89 & \\
\hline Male gender & 27 & 90 & 29 & 97 & NS \\
\hline \multicolumn{6}{|l|}{ Risk factors } \\
\hline Hypertension & 14 & 47 & 4 & 13 & 0.046 \\
\hline Diabetes (insulin) & 1 & 3 & 0 & 0 & NS \\
\hline Diabetes (NID) & 2 & 7 & 3 & 10 & NS \\
\hline Current smoker & 12 & 40 & 13 & 43 & NS \\
\hline Ex-smoker & 7 & 23 & 8 & 27 & NS \\
\hline Multifocal vascular disease & 4 & 13 & 3 & 10 & NS \\
\hline Obesity & 2 & 7 & 1 & 3 & NS \\
\hline \multicolumn{6}{|l|}{ Previous MI } \\
\hline Fresh, $<6$ weeks & 1 & 3 & 4 & 13 & NS \\
\hline Old, $>6$ weeks & 15 & 50 & 4 & 13 & 0.035 \\
\hline \multicolumn{6}{|l|}{ Preoperative CCS angina class } \\
\hline 3 & 14 & 47 & 15 & 50 & NS \\
\hline 4 & 16 & 53 & 15 & 50 & NS \\
\hline Elective operation & 29 & 97 & 28 & 93 & NS \\
\hline
\end{tabular}

Mean \pm SD where applicable. NID = Non-insulin-dependent MI = myocardial infarction; CCS = Canadian Cardiovascular Society's angina classification; NS = nonsignificant statistical difference.

\section{Patient Characteristics}

Patient profiles did not differ between the groups, except for a significantly higher rate of patients with arterial hypertension and previous myocardial infarction ( $>6$ weeks prior to surgery) in group 1 (table 1). There was a significantly higher number of patients in group 1 with pathological lipid values: 29/30 (97\%) compared to $12 / 30(40 \%)$ patients in group 2 (p < $0.001)$. The distribution of elevated total serum cholesterol and serum triglycerides is shown in table 2 . There were only 3 patients with established hypercholesterolemia in group 1 on treatment with lipid-lowering drugs at the time of surgery (10\%). However, all 3 patients had serum cholesterol values well above the upper normal limit: 6.6, 6.7 and $6.9 \mathrm{mmol} / \mathrm{l}$, respectively (normal value $<6.2 \mathrm{mmol} / \mathrm{l}$ ). In group 2 , the 2 patients with hyperlipidemia were adequately treated with lipidlowering drugs and had both serum cholesterol values within normal limits prior to surgery.

The mean preoperative left ventricular ejection fraction was $0.48 \pm 0.08$ (ranging from 0.38 to 0.65 ). Eleven patients $(18 \%, 11 / 60)$ had left main coronary artery stenosis. Seventy to eighty-seven percent $(52 / 60)$ of the patients had triple coronary artery disease, without statistically significant differences between the groups.

\section{Operation Data}

There were no differences in operative data between the groups. Anesthesia, CPB and surgical techniques were standardized and did not change during the study period. Myocardial revascularization was 
Table 2. Distribution of total serum cholesterol, serum triglycerides and combination thereof, in 30 consecutive patients undergoing elective $\mathrm{CABG}$ who subsequently developed postoperative thrombocytosis (group 1) and 30 consecutive patients undergoing CABG with postoperative platelet counts within normal limits (controls, group 2)

\begin{tabular}{|c|c|c|c|c|c|}
\hline & \multicolumn{2}{|c|}{ Group $1(n=30)$} & \multicolumn{2}{|c|}{ Group $2(\mathrm{n}=30)$} & \multirow[t]{2}{*}{$\mathrm{p}$ value } \\
\hline & $\mathrm{n}$ & $\%$ & $\mathrm{n}$ & $\%$ & \\
\hline Hypercholesterolemia & 8 & 26.7 & 1 & 3.3 & NS \\
\hline Hyperglyceridemia & 4 & 13.3 & 10 & 33.4 & NS \\
\hline Hypercholesterolemia and triglyceridemia & 17 & 57.7 & 1 & 3.3 & $<0.001$ \\
\hline Normal serum cholesterol and triglyceride values & 1 & 3.3 & 18 & 60.0 & $<0.001$ \\
\hline $\begin{array}{l}\text { Total number of patients with preoperative } \\
\text { hyperlipidemia }\end{array}$ & $29 / 30$ & 96.7 & 12.30 & 40.0 & $<0.001$ \\
\hline
\end{tabular}

NS = Nonsignificant statistical difference.

performed during normothermic $\mathrm{CPB}\left(35-37^{\circ} \mathrm{C}\right)$. For myocardial protection, cold intermittent crystalloid cardioplegia (St. Thomas' II, $8-10^{\circ} \mathrm{C}$, including allopurinol $100 \mathrm{mg} / \mathrm{l}$ ) together with topical hypothermia with slush were employed. Initially $1,000 \mathrm{ml}$ cardioplegic solution was infused into the aortic root under low pressure. Cardioplegia $(500 \mathrm{ml})$ was repeated every $30 \mathrm{~min}$ or whenever electrical activity reappeared. As routine, we used the sequential bypass grafting technique earlier described in detail [4] and the internal thoracic artery was utilized as bypass conduit to LAD in 58 of the 60 patients (97\%) in this series. No other arterial conduits were used in the present series. On an average there were $4.0 \pm 1.3$ distal anastomoses/ patient (ranging from 2 to 6 ). Coronary artery thrombendarterectomy was performed in $8 \%$ of the patients $(5 / 60)$. The total ischemia time (aortic cross-clamping, minutes) and mean $\mathrm{CPB}$ time did not differ between the groups $(56.8 \pm 16.3$ and $75.9 \pm 21.3 \mathrm{~min}$, respectively).

\section{Statistical Analysis}

Student's t test, Mann-Whitney and Fischer's exact test were employed to assess differences between values for statistical significance where appropriate. Differences were considered significant at a probability level of $p<0.05$. Data was compiled as mean \pm standard deviation.

\section{Results}

\section{Mortality and Morbidity}

There was no hospital mortality during the study period in either of the groups. There was no diagnosis of nonfatal myocardial infarction, defined as appearance of new Q waves, or significant loss of $\mathrm{R}$-wave forces, together with peak creatine phosphokinase MB fractions greater than $10 \%$ of total creatine phosphokinase in this series. A transient low cardiac output (cardiac index $<2.0$ liters/ $\mathrm{min} / \mathrm{m}^{2}$ ) occurred in 2 patients only postoperatively (1 in each of the groups), and both were successfully overcome by inotropic pharmacological support (dopamine and dobutamine) during 3 and 4 days, respectively. Transient supraventricular arrhythmia was observed postoperatively in 14 patients and short episodes of ventricular arrhythmia occurred in 2 patients postoperatively. Another 2 patients developed postoperative bronchopneumonia, which in both cases were successfully treated with antibiotics and respiratory physiotherapy. The postoperative morbidity did not reveal any group differences. 
Fig. 1. Mean platelet count, $\times 1,000 / \mathrm{mm}^{3}$, in 30 patients undergoing $\mathrm{CABG}$, who subsequently developed postoperative thrombocytosis (platelets $>400,000 / \mathrm{mm}^{3}$, group $1, \mathbf{\Delta})$ compared to mean platelet count in 30 patients operated in the same manner, but who did not develop postoperative thrombocytosis ('normal' platelet response, group 2, O).

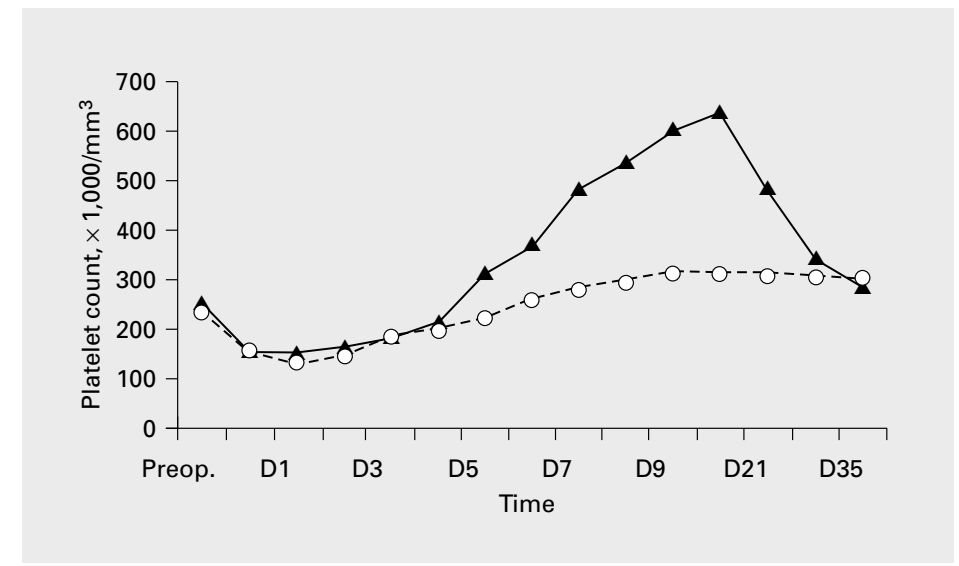

\section{Symptomatic Graft Occlusions}

During the first 7 postoperative days no symptomatic graft occlusions occurred in any of the two groups. However, during the follow-up period, 3 of the patients in group 1 had symptomatic vein graft anastomosis occlusions at 14,18 and 21 days postoperatively, confirmed by angiography. The 1st patient was found to have occluded distal anastomosis to a good-quality marginal branch of the circumflex artery, while the remaining anastomoses in the vein sequence were patent. The 2nd patient had an occlusion of the vein graft to a nondominant small right coronary artery $(1.5 \mathrm{~mm})$. Both patients were diagnosed due to reappearance of angina, which was controlled by medical therapy. Myocardial infarction was not confirmed in either of these patients. The 3rd patient, however, presented with an acute evolving anterior myocardial infarction; angiography revealed thrombosis of the LAD-vein graft, and a reoperation was successfully performed using an ITA graft. In all the patients with symptomatic vein graft occlusion, the graft occlusion coincided with peak platelet count, 804,000, 905,000 and $872,000 / \mathrm{mm}^{3}$, respectively, which was also among the highest recorded platelet values in the series, and there were no obvious reasons to suspect technical errors.

Postoperative thrombocytosis, as the only postoperative complication, occurred in 17 patients in group 1.

\section{Platelet Counts}

Mean platelet count in both groups, preoperatively and at various times postoperatively, is presented in figure 1. The postoperative platelet counts in patients with postoperative thrombocytosis (group 1) differed significantly from the configuration of the 'normal' platelet response following CABG (group 2). In group 1 thrombocytosis was diagnosed on an average $6.1 \pm 1.5$ days postoperatively (ranging from 5 to 8 days). However, the peak platelet count was reached not until $7 \pm 3$ days later or at $14 \pm 4$ days postoperatively (minimum 6 and maximum 21 days after surgery). The highest platelet count measured was $905,000 / \mathrm{mm}^{3}$, and the average peak value was $688,000 \pm 120,000 / \mathrm{mm}^{3}$, ranging from 446,000 to $905,000 / \mathrm{mm}^{3}$ (table 3 ). The mean duration of postoperative thrombocytosis in this series was $21 \pm 7$ days (ranging from 7 to 34 days). Furthermore, it was observed that the higher the platelet peak value 
Table 3. Postoperative thrombocytosis following CABG in group 1: time from diagnosis to peak platelet value, peak platelet value, time from peak platelet value to normalization of platelet count and total duration of thrombocytosis in 30 patients

\begin{tabular}{|c|c|c|c|c|}
\hline $\begin{array}{l}\text { Patient } \\
\text { No. }\end{array}$ & $\begin{array}{l}\text { Time from } \\
\text { diagnosis to peak } \\
\text { platelet value } \\
\text { days }\end{array}$ & $\begin{array}{l}\text { Peak platelet } \\
\text { value } \\
\times 10^{3} / \mathrm{mm}^{3}\end{array}$ & $\begin{array}{l}\text { Time from } \\
\text { peak to normal } \\
\text { platelet value } \\
\text { days }\end{array}$ & $\begin{array}{l}\text { Duration of } \\
\text { thrombo- } \\
\text { cytosis, days }\end{array}$ \\
\hline 1 & 2 & 446 & 5 & 7 \\
\hline 2 & 14 & 905 & 20 & 34 \\
\hline 3 & 2 & 712 & 19 & 28 \\
\hline 4 & 7 & 872 & 26 & 33 \\
\hline 5 & 5 & 672 & 23 & 21 \\
\hline 6 & 5 & 681 & 9 & 14 \\
\hline 7 & 7 & 696 & 17 & 24 \\
\hline 8 & 7 & 532 & 8 & 15 \\
\hline 9 & 7 & 541 & 9 & 16 \\
\hline 10 & 8 & 612 & 14 & 22 \\
\hline 11 & 7 & 642 & 15 & 14 \\
\hline 12 & 3 & 660 & 19 & 22 \\
\hline 13 & 7 & 615 & 14 & 21 \\
\hline 14 & 7 & 804 & 17 & 24 \\
\hline 15 & 9 & 812 & 23 & 32 \\
\hline 16 & 8 & 617 & 14 & 22 \\
\hline 17 & 6 & 780 & 19 & 25 \\
\hline 18 & 1 & 499 & 7 & 8 \\
\hline 19 & 14 & 618 & 16 & 23 \\
\hline 20 & 1 & 544 & 6 & 7 \\
\hline 21 & 6 & 642 & 15 & 13 \\
\hline 22 & 7 & 900 & 20 & 28 \\
\hline 23 & 8 & 660 & 5 & 23 \\
\hline 24 & 9 & 713 & 19 & 22 \\
\hline 25 & 7 & 872 & 19 & 17 \\
\hline 26 & 12 & 804 & 14 & 30 \\
\hline 27 & 10 & 672 & 17 & 20 \\
\hline 28 & 8 & 812 & 25 & 24 \\
\hline 29 & 7 & 681 & 22 & 21 \\
\hline 30 & 8 & 617 & 18 & 15 \\
\hline Mean \pm SD & $7 \pm 3$ & $688 \pm 120$ & $16 \pm 6$ & $21 \pm 7$ \\
\hline Maximum & 14 & 905 & 26 & 34 \\
\hline Minimum & 1 & 446 & 5 & 7 \\
\hline
\end{tabular}

reached the longer was the total duration of the thrombocytosis, e.g. with platelet peak values $\geq 700,000 / \mathrm{mm}^{3}$ the duration was significantly longer than if the platelet peak values were lower than $700,000 / \mathrm{mm}^{3}: 27.0 \pm$ $5.2(\mathrm{n}=11)$ and $17.1 \pm 4.1(\mathrm{n}=19)$ days, respectively $(\mathrm{p}<0.001)$.

The incidence of symptomatic vein graft occlusion was found higher when the peak platelet count was $\geq 700,000 / \mathrm{mm}^{3}$. Three out 
Fig. 2. Mean serum hemoglobin, $\mathrm{g} / \mathrm{dl}$, in 30 patients undergoing CABG, who subsequently developed postoperative thrombocytosis (group 1, $\mathbf{\Delta}$ ) and in 30 control patients without postoperative thrombocytosis (group 2, O).

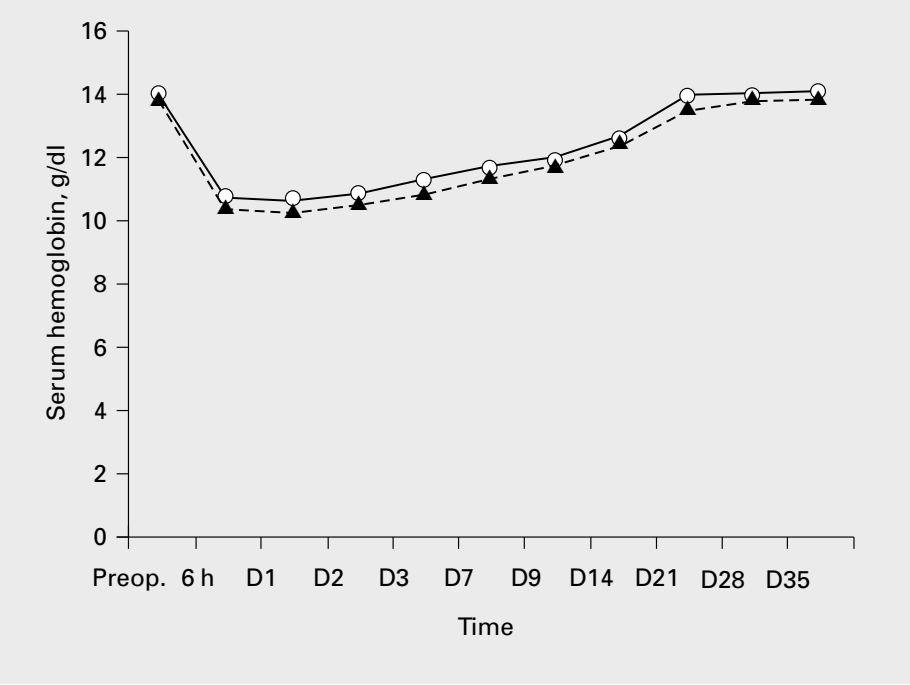

of 11 patients had distal graft anastomosis occlusions during the follow-up, compared to no diagnosed symptomatic vein graft occlusions in 19 patients with platelet peak values less than $700,000 / \mathrm{mm}^{3}$.

The average return time from peak platelet value to platelet count within normal limits was $16 \pm 6$ days (ranging from 5 to 26 days; table 3 ).

\section{Serum Hemoglobin}

The serum hemoglobin levels following CABG with CPB in patients who developed postoperative thrombocytosis (group 1) did not differ from control patients (group 2), thus indicating that anemia is unlikely to be a triggering factor for the development of postoperative thrombocytosis (fig. 2).

\section{Mean Platelet Volume and Platelet \\ Adhesivity Tests}

The mean platelet volume did not differ between the groups preoperatively, but was significantly higher in group 1 patients from the 5 th postoperative day and onwards. Plate- let adhesivity tests and total serum creatine kinase did not differ significantly through the study period, not even during the peak thrombocytosis.

\section{Serum Cholesterol and Triglycerides}

In group 1 , the mean preoperative total serum cholesterol value was $6.82 \pm 0.83$ $\mathrm{mmol} / \mathrm{l}$ and decreased to $5.72 \pm 1.13 \mathrm{mmol} / \mathrm{l}$ 2 weeks after CABG (day 14, p $=0.009$ ). Serum triglycerides were $2.15 \pm 0.73 \mathrm{mmol} / 1$ preoperatively and $1.72 \pm 0.56 \mathrm{mmol} / \mathrm{l}$ on day $14(p=0.0753$, NS). (Upper normal limits in our laboratory are: total serum cholesterol $<6.2 \mathrm{mmol} / \mathrm{l}$, total serum cholesterol/HDL cholesterol quota $<5$ and serum triglycerides $<1.80 \mathrm{mmol} / \mathrm{l})$.

Total serum cholesterol as well as serum triglyceride levels decreased immediately after surgery, followed by a gradual and slow increase observed in both study groups. Table 4 shows the distribution of various hyperlipidemic states in patients from the two groups preoperatively and at 14 and 28 days postoperatively. 
Table 4. Distribution of total serum cholesterol, serum triglycerides and combination thereof, preoperatively and on the 14th and 28th day postoperatively in 30 consecutive patients undergoing elective coronary artery, who postoperatively developed thrombocytosis (group 1) and 30 consecutive patients undergoing CABG with postoperative platelet counts within normal limits (controls, group 2)

\begin{tabular}{|c|c|c|c|c|c|}
\hline & \multicolumn{2}{|c|}{ Group $1(n=30)$} & \multicolumn{2}{|c|}{ Group $2(n=30)$} & \multirow[t]{2}{*}{$\mathrm{p}$ value } \\
\hline & $\mathrm{n}$ & $\%$ & $\mathrm{n}$ & $\%$ & \\
\hline \multicolumn{6}{|l|}{ Preoperative } \\
\hline hyperlipidemia & 29 & 96.7 & 12 & 40.0 & $<0.001$ \\
\hline Day 14 p.o. & 20 & 66.7 & 10 & 33.3 & NS \\
\hline Day 28 p.o. & 27 & 90.0 & 11 & 36.7 & 0.0019 \\
\hline \multicolumn{6}{|l|}{ Preoperative } \\
\hline hypercholesterolemia & 8 & 26.7 & 1 & 3.3 & NS \\
\hline Day 14 p.o. & 5 & 16.7 & 1 & 3.3 & NS \\
\hline Day 28 p.o. & 11 & 36.7 & 1 & 3.3 & 0.032 \\
\hline \multicolumn{6}{|l|}{ Preoperative } \\
\hline hypercholesterolemia & 4 & 13.3 & 10 & 33.4 & NS \\
\hline Day 14 p.o. & 8 & 26.7 & 8 & 26.7 & NS \\
\hline Day 28 p.o. & 7 & 23.3 & 9 & 30.0 & NS \\
\hline \multicolumn{6}{|l|}{ Preoperative combined } \\
\hline hypercholesterolemia and & & & & & \\
\hline hypertriglyceridemia & 17 & 57.7 & 1 & 3.3 & $<0.001$ \\
\hline Day 14 p.o. & 7 & 23.3 & 1 & 3.3 & NS \\
\hline Day 28 p.o. & 9 & 30.0 & 1 & 3.3 & $<0.001$ \\
\hline \multicolumn{6}{|l|}{ Preoperative normal } \\
\hline cholesterol and triglycerides & 1 & 3.3 & 18 & 60.0 & $<0.001$ \\
\hline Day 14 p.o & 10 & 33.3 & 20 & 66.7 & NS \\
\hline Day 28 p.o. & 3 & 10.0 & 19 & 63.4 & 0.0012 \\
\hline
\end{tabular}

The total number of patients in group 1 with pathologically elevated total serum cholesterol and serum triglycerides decreased from 29 patients prior to surgery to 20 patients 2 weeks postoperatively. Nevertheless, at 28 days postoperatively, 27 patients had represented pathological lipid values (table 4).

Perhaps more important was that in group 1 , a significantly larger number of patients presented with pathological total serum cho-
lesterol/HDL cholesterol quota compared to the control group (group 2). This difference remained significantly different at days 7,14 and 28 postoperatively (table 5 ).

\section{Discussion}

Various platelet disturbances are known to occur following extracorporeal circulation, such as thrombocytopenia and platelet dys- 
Table 5. Patients with pathological total serum cholesterol/HDL cholesterol preoperatively and 7, 14 and 28 days postoperatively in 30 consecutive patients undergoing elective CABG who subsequently developed postoperative thrombocytosis (group 1) and 30 consecutive patients undergoing CABG with postoperative platelet counts within normal limits (controls, group 2)

\begin{tabular}{|c|c|c|c|c|c|}
\hline & \multicolumn{2}{|c|}{$\begin{array}{l}\text { Group 1 } \\
(\mathrm{n}=30)\end{array}$} & \multicolumn{2}{|c|}{$\begin{array}{l}\text { Group } 2 \\
(\mathrm{n}=30)\end{array}$} & \multirow[t]{2}{*}{$\mathrm{p}$ value } \\
\hline & $\mathrm{n}$ & $\%$ & $\mathrm{n}$ & $\%$ & \\
\hline Preoperative quota & 25 & 83.3 & & 13.3 & $<0.001$ \\
\hline Mean $\pm \mathrm{SD}$ & \multicolumn{2}{|c|}{$6.55-1.32$} & \multicolumn{2}{|c|}{$4.82-1.30$} & $<0.001$ \\
\hline Day 7 postoperative quota & 24 & 80.0 & 5 & 16.7 & $<0.001$ \\
\hline Mean \pm SD & \multicolumn{2}{|c|}{$6.32-1.27$} & \multicolumn{2}{|c|}{$4.86-1.30$} & NS \\
\hline Day 14 postoperative quota & 23 & 76.7 & 2 & 6.7 & $<0.001$ \\
\hline Mean $\pm \mathrm{SD}$ & \multicolumn{2}{|c|}{$6.35-1.08$} & \multicolumn{2}{|c|}{$4.22-0.86$} & 0.0067 \\
\hline Day 28 postoperative quota & & 90.0 & & 30.0 & $<0.001$ \\
\hline Mean $\pm \mathrm{SD}$ & \multicolumn{2}{|c|}{$6.64-1.76$} & \multicolumn{2}{|c|}{$4.87-1.18$} & $<0.001$ \\
\hline
\end{tabular}

NS = Nonsignificant statistical difference

function, causing bleeding as well as postoperative thrombocytosis, associated with an increased risk for graft occlusion [1-3]. Postoperative thrombocytosis indicates an abnormally high number of platelets in the circulation [5]. This could be a result of either a mobilization of existing extravascular pooled platelets, e.g. after vigorous exercise [6], or more commonly an accelerated platelet production due to an underlying disorder or condition, e.g. anemia, cancer and inflammation/ infection, where the platelets act as acute phase reactants [7]. Another possibility is delayed or impaired clearance. Sometimes when no underlying cause can be found, then it is referred to as essential thrombocytosis [8].

The importance of increased platelet numbers in the thrombotic process is not fully understood. However, it has been established that both multiple coronary artery thrombosis as well as increased risk for late vein graft occlusion and myocardial infarction is observed in patients with thrombocytosis [2,9].
The underlying mechanism for postoperative thrombocytosis following CABG with cardiopulmonary bypass is not yet fully understood. In a recent prospective study we have documented that the serum cholesterol level was significantly higher in a group of patients undergoing CABG who subsequently developed thrombocytosis, compared to patients without postoperative thrombocytosis [3]. There were no differences between the groups regarding hemostasis, coagulation and anti-inflammatory parameters, thus suggesting that postoperative thrombocytosis could be linked to a lipid dysfunction, e.g. lipoprotein (a), which has been associated with platelet function, as well as having a genetic variation [3]. In other studies a relationship between platelet reactivity and serum lipids has been demonstrated: increased sensitivity to aggregating agents in patients with hypercholesterolemia [10], due to increased cholesterol content in the platelet membrane [11], and shortened platelet survival times in patients 
with coronary artery disease and hyperlipoproteinemia [12]. The plasma concentration of lipoprotein (a) has been found highly positively correlated with the incidence of cardiovascular disease [13] and recent studies suggest that lipoprotein (a) may affect thrombosis, fibrinolysis, or both, possibly by interfering with the normal clotting process [14]. The possible association between postoperative thrombocytosis and hypercholesterolemia was yet again suggested by the present study, while anemia as a possible underlying cause, by triggering increased bone marrow activity, could be ruled out. Also inflammation and infection was ruled out as trigger mechanism.

The relative high incidence of thrombocytosis observed in this and previous studies compared to few other reports in the cardiothoracic literature is probably due to that in most studies platelet counts are rarely sampled beyond the 6 th- 7 th postoperative day.

The present study provides yet another evidence of the potential danger of developing thrombocytosis following CABG surgery using CPB. The risk of vein graft occlusion is highly increased. Interestingly, the symptomatic vein graft occlusions that occurred in 3 of the patients coincided with the time when these patients reached their peak platelet values. Furthermore, our data suggest that the higher the platelet peak value goes, the higher is the risk for a symptomatic graft occlusion, despite treatment with acetylsalicylic acid $100 \mathrm{mg}$ daily. This supports previous findings regarding the inability of low-dose acetylsalicylic acid to prevent graft thrombosis, once postoperative thrombocytosis is established [3].

It was confirmed that on an average postoperative thrombocytosis is diagnosed around the 7 th postoperative day, but that there could be a substantial delay in reaching the peak value of the platelet count, with the longest delay being 3 weeks postoperatively.
Sometimes postoperative thrombocytosis is associated with very high platelet counts and the postoperative thrombocytosis may last as long as 5 weeks. This emphasizes the need for a very close surveillance long after hospital discharge, and the necessity for a more efficient treatment, perhaps even plateletpheresis in some cases, once platelet count reaches extreme levels. Alternative methods such as indomethacin or dextran could also be explored. Even though a large proportion of the patients normalized their serum cholesterol and serum triglycerides during the immediate postoperative period, at 2 weeks $77 \%$ of them had a pathological cholesterol/HDL cholesterol quota. At 4 weeks postoperatively the above-mentionend quota reached $90 \%$. These patients ought to be closely monitored and treated with lipid-lowering drugs. Currently there are studies going on, on how to optimize the treatment of postoperative thrombocytosis and the introduction of possible preventive measures preoperatively. 


\section{References}

1 McKenzie FN, Dhall DP, Arfors KE, Nordlund S, Matheson NA: Blood platelet behavior during and after open-heart surgery. Br J Med 1969;2:795-798.

2 Schmuziger M, Christenson JT, Maurice J, Simonet F, Velebit V: Reactive thrombocytosis after coronary bypass surgery: An important risk factor. Eur J Cardiothorac Surg 1995;9:393-398.

3 Christenson JT, Gras PA, Grosclaude A, Simonet F, Schmuziger M: Reactive thrombocytosis following coronary artery bypass surgery: A possible link to a lipid dysfunction. J Cardiovasc Surg 1996;37: 491-498.

4 Christenson JT, Schmuziger M: How serious is a proximal occlusion of a posterolateral sequential bypass? Tex Heart Inst J 1996;23:201206.
5 Davis WM, Mendez Ross AO: Thrombocytosis and thrombocythemia. Am J Clin Pathol 1973;59: 243-247.

6 Dawson AA, Ogston D: Exerciseinduced thrombocytosis. Acta Haematol 1969;42:421-426.

7 Handin RI: Disorders of the platelet and vessel wall; in Isselbacher $\mathrm{KJ}$, Nraunwald E, Wilson JD, Matin JB, Fauci AS, Caper DL (eds): Harrison's Principles of Internal Medicine, ed 13. New York, McGrawHill, 1994, pp 1798-1803.

8 Pearson TC: Primary thrombocythemia: Diagnosis and management. Br J Haematol 1991;78:145152.

9 Hamada Y, Matsuda Y, Fujii B, Ohno H, Takashiba K, Ebihara H, Hyakuna E: Multiple coronary thrombosis in a patient with thrombocytosis. Clin Cardiol 1989;12. 723-724.

10 Nordoy A, Rodset JM: Platelet phospholipids and their function in patients with ischemic heart disease. Acta Med Scand 1970;188:133136.
11 Carvalho AC, Colman RW, Lees RS: Platelet function in hyperlipoproteinemia. N Engl J Med 1974; 290:434-438.

12 Shattil SJ, Anaya-Galindo R, Bennett J, Colman RW, Cooper RA: Platelet hypersensitivity induced by cholesterol incorporation. J Clin Invest 1975;55:636-641.

13 Dahlén GH, Guyton JR, Attar M, Farmer JA, Kautz JA, Gotto AM Jr: Association of levels of lipoprotein Lp(a), plasma lipids, and other lipoproteins with coronary artery disease documented by angiography. Circulation 1986;74:758-765.

14 Hajjar KA, Gavish D, Breslow JL, Nachman RL: Lipoprotein (a) modulation of endothelial cell surface fibrinolysis and its potential role in atherosclerosis. Nature 1989;339: 303-305. 